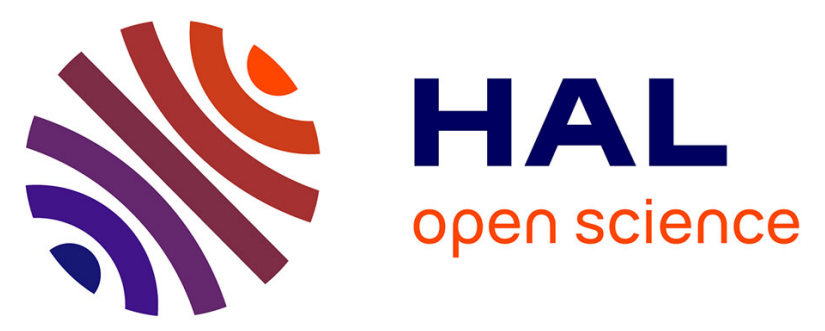

\title{
Best-practice interventions to reduce socioeconomic inequalities of coronary heart disease mortality in UK: a prospective occupational cohort study.
}

Mika Kivimäki, Martin J Shipley, Jane E Ferrie, Archana Singh-Manoux, G David Batty, Tarani Chandola, Michael G. Marmot, George Davey Smith

\section{To cite this version:}

Mika Kivimäki, Martin J Shipley, Jane E Ferrie, Archana Singh-Manoux, G David Batty, et al.. Bestpractice interventions to reduce socioeconomic inequalities of coronary heart disease mortality in UK: a prospective occupational cohort study.. The Lancet, 2008, 372 (9650), pp.1648-54. 10.1016/S01406736(08)61688-8 . inserm-00340645

\section{HAL Id: inserm-00340645 https://www.hal.inserm.fr/inserm-00340645}

Submitted on 21 Nov 2008

HAL is a multi-disciplinary open access archive for the deposit and dissemination of scientific research documents, whether they are published or not. The documents may come from teaching and research institutions in France or abroad, or from public or private research centers.
L'archive ouverte pluridisciplinaire HAL, est destinée au dépôt et à la diffusion de documents scientifiques de niveau recherche, publiés ou non, émanant des établissements d'enseignement et de recherche français ou étrangers, des laboratoires publics ou privés. 
Lancet theme issue "Determinants of Health Inequalities" Nov 82008

Estimating the impact of 'best-practice' interventions on reducing socioeconomic inequalities in coronary heart disease mortality in a working population: the Whitehall study

Mika Kivimäki, Martin J. Shipley, Jane E. Ferrie, Archana Singh-Manoux, G. David Batty, Tarani Chandola, Michael G. Marmot, George Davey Smith

Manuscript statistics: 3664 words in text; 272 in abstract; 41 references; 3 tables; no figures.

Department of Epidemiology and Public Health, University College London, 1-19 Torrington Place, London WC1E 6BT, UK

Prof. Mika Kivimaki PhD

Martin J. Shipley MSc

Jane E. Ferrie $\mathrm{PhD}$

Archana Singh-Manoux $\mathrm{PhD}$

Tarani Chandola DSc

Prof. Sir Michael G. Marmot PhD

INSERM, U687-IFR69, Hopital Paul Brousse, 16 avenue Paul Vaillant Couturier, Villejuif Cedex 94807, France

Archana Singh-Manoux PhD 
MRC Social \& Public Health Sciences Unit, 4 Lilybank Gardens, Glasgow, UK, G12 8RZ, UK

G. David Batty PhD

MRC Centre for Causal Analyses in Translational Epidemiology, Department of Social Medicine, University of Bristol, UK

Prof. George Davey Smith DSc

Correspondence to: Prof. M Kivimaki, Department of Epidemiology and Public Health, University College London, 1-19 Torrington Place, London WC1E 6BT, UK. Tel. +44 20 7679 8260; Fax +44 207419 6732. E-mail: m.kivimaki@ucl.ac.uk 


\section{SUMMARY}

Background The extent to which the successful implementation of the most effective ('best-practice') interventions to modify coronary heart disease (CHD) risk factors could reduce socioeconomic inequalities in CHD mortality at a population level is not known.

Methods We examined this issue in an occupational cohort of 17,186 male civil servants aged 40-69 years at study induction in 1967-70. Socioeconomic position was based on employment grade. We calculated the potential reduction in excess CHD mortality among men of low compared to high socioeconomic position using either best-practice interventions (reduction in systolic blood pressure $10 \mathrm{~mm} \mathrm{Hg}$, total cholesterol $2 \mathrm{mmol} / \mathrm{L}$, blood glucose $1 \mathrm{mmol} / \mathrm{L}$ among pre-diabetics; prevalence of non-insulin dependent diabetes halved; complete cessation of cigarette smoking) or, for comparison, return to primordial levels of risk factors (whole population of never smokers with optimal risk factor levels).

Findings Less than $2 \%$ of men were never smokers with optimal risk factor levels. Fifteen year risk of CHD death per 100 men standardised to age 55 was 11.0 for men in the low employment grade group and 7.5 in the high grade group. Population-wide best practice interventions would reduce CHD mortality by $57 \%$, and the difference in CHD mortality between socioeconomic groups by $69 \%$. For primordial prevention, the corresponding reductions would be $73 \%$ and $86 \%$, respectively.

Interpretation Results from an occupational cohort suggest that current best practice interventions to reduce classic coronary risk factors, if successfully implemented in both 
high and low socioeconomic groups, could eliminate most of the socioeconomic differences in CHD mortality. Modest further benefits would result if the classic coronary risk factors could be reduced to primordial levels for the whole population.

Funding: Department of Health and Social Security, Tobacco Research Council, British Heart Foundation, Medical Research Council, European Research Council, Wellcome Trust (UK), Academy of Finland (Finland). 


\section{INTRODUCTION}

There is uncertainty regarding the best ways to reduce socioeconomic inequalities in coronary heart disease (CHD), a leading cause of death.(1-3) Studies have assessed the contribution of various risk factors to socioeconomic inequalities by comparing the relative risk of $\mathrm{CHD}$ between high and low socioeconomic groups before and after adjustment for these risk factors. (4-7) The problem with this method is that it does not take into account the extent to which reduction in each risk factor is feasible; it simply approximates what would happen after standardization to the risk factor distribution in the total study population.

Classic, well established risk factors that explain most CHD incidence are high blood pressure, high cholesterol, diabetes mellitus, and cigarette smoking.(8-10) The most successful ('best-practice') pharmacological and lifestyle interventions to date have managed to reduce systolic blood pressure on average by approximately $10 \mathrm{~mm} \mathrm{Hg},(11)$ total cholesterol by $2 \mathrm{mmol} / \mathrm{L},(12)$ blood glucose among pre-diabetics by $1 \mathrm{mmol} / \mathrm{L}$, and halve the prevalence of non-insulin dependent diabetes in adults.(13) Using existing data bases it is possible to estimate the extent to which successful implementation of these best-practice interventions could reduce socioeconomic inequalities in CHD at the population level. $(9,14)$

In this study, we estimate - both in absolute and relative terms - what would happen to socioeconomic inequalities in CHD if these best-practice risk reductions applied in both high and low socioeconomic groups. We also examine the additional potential for risk reduction if all smokers quit. Unlikely though this may seem, new aggressive anti- 
smoking policies and the reduction in smoking among UK men from $82 \%$ to $26 \%$ over the past six decades render at least an approximation to this situation more plausible than at first envisaged.(15)

To provide an extreme comparison, we also estimate the effects on socioeconomic inequalities of a primordial prevention strategy based on risk factor levels well below levels currently observed in westernised societies. It is clear that blood pressure elevations with age are not physiologically inevitable(16) and diabetes prevalence is very low in the absence of westernised diets and obesity levels. $(17,18)$ Theoretically, outside of the small proportion of people with a strong genetic predisposition to hypercholesterolaemia, there is no reason why cholesterol levels could not be kept low throughout life(19) and initiation into tobacco use eliminated. We therefore quantify the risk reduction associated with systolic blood pressure $\leq 120 \mathrm{mmHg}$, cholesterol concentration $\leq 5.0 \mathrm{mmol} / \mathrm{L}$, postload blood glucose $\leq 4.6 \mathrm{mmol} / \mathrm{L}(20)$ and never smoking on socioeconomic inequalities in CHD.

\section{METHODS}

\section{Study population}

The target population of the Whitehall study was 19,019 non-industrial London-based male government employees aged from 40 to 69 years at screening between September 1967 and January 1970 (response 74\%).(21)

\section{Assessment of risk factors at baseline}

Socioeconomic position was based on civil service employment grade. To obtain sufficient numbers for each socioeconomic group and to simplify data interpretation, we 
dichotomised the level of employment grade into high (administrative, professional or executive) or low (clerical, messenger and other unskilled manual grades). Employment grade was not comparable to the rest of the sample for 886 men from the Diplomatic Service and the British Council so these individuals were excluded from all analyses. A single blood pressure reading was taken from the left arm by a trained observer using a London School of Hygiene sphygmomanometer.(22) Systolic blood pressure was recorded at the first appearance of the Korotkoff sounds. A capillary sample of blood was taken from the ear lobe after an overnight fast. Participants then drank a 50-g anhydrous dextrose preparation. Plasma cholesterol concentration was measured using the standard Technicon method N24a.(21) Two hours later a second blood sample was taken. Postload blood glucose concentration was measured by the ferricyanide reduction method on an autoanalyser (Technicon method N-9a). Those with self-reported diabetes did not undertake the glucose tolerance test and those with a post-load blood glucose $\geq 11.1$ $\mathrm{mmol} / \mathrm{L}(\geq 200 \mathrm{mg} / \mathrm{dl})$ were categorised as non-insulin dependent diabetics (non-IDDM). Diabetic participants on insulin treatment were classified as insulin dependent diabetics (IDDM). Smoking status was self-reported.

\section{Ascertainment of coronary heart disease mortality}

Fifteen-year mortality data were obtained from the National Health Services (NHS) Central Registry using the NHS identification number assigned to each UK citizen. As these records do not cover deaths among people who emigrated from the UK and died abroad, participants flagged as embarkees were censored at the date of embarkation. CHD death was indicated by codes 410-414 (International Classification of Diseases (ICD) 8 and 9) and codes I20-I25 (ICD-10). 


\section{Statistical analysis}

We excluded from the analysis men who had any missing values for the risk factors of interest - systolic blood pressure $(n=6)$, cholesterol $(n=709)$, smoking status $(n=8)$, blood glucose/diabetes $(\mathrm{n}=135)$. Difficulties in retrieving a sufficient sample of blood using the capillary method from an incision in the earlobe may have contributed to the higher rate of missing values for cholesterol (3.7\%), but this missingness was nondifferential by socioeconomic position $(\mathrm{p}=0.38)$. We also excluded 16 men who had died but for whom the cause of death was unknown. In all, 17,186 men were included in the analysis.

Follow-up after baseline was limited to 15 years to minimise the possible dilution of effects associated with extended mortality surveillance and to cover a period when statins had yet to become a commonly prescribed treatment for high cholesterol.(21, 23) In analyses of baseline characteristics and mortality, the prevalence of risk factors and 15year CHD mortality rates between men in the high and low employment grade were adjusted for age (using 5 year age groups) by the direct standardisation method and compared using the Mantel-Haenszel test. For continuous measures, linear regression was used to calculate age-adjusted least squares means, and differences between the grades were tested using the dichotomous grade term.

\section{Estimation for best-practice interventions}

The relationship between risk factors and CHD mortality was estimated using the parametric Weibull distribution to model the survival function. Using this model, hazard ratios associated with each risk factor and their $95 \%$ confidence intervals were calculated per $10 \mathrm{~mm} \mathrm{Hg}$ increase for systolic blood pressure, per $2 \mathrm{mmol} / \mathrm{L}$ increase for total 
cholesterol, and for current smokers versus ex- or never-smokers. Due to the threshold effect of glucose on CHD mortality observed previously in this study,(20) we calculated the hazard ratio per $1 \mathrm{mmol} / \mathrm{L}$ increase for post-load blood glucose concentrations above $4.6 \mathrm{mmol} / \mathrm{L}$ and the hazard ratio for presence of insulin dependent and non-insulin dependent diabetes compared with those with blood glucose concentrations below 4.6 $\mathrm{mmol} / \mathrm{L}$. We adjusted for age using both a linear and quadratic term and included a dichotomous term for employment grade. All these hazards ratios and confidence intervals were virtually identical to those computed using a Cox proportional hazards model. Using the Weibull model, the risk of death from CHD over any time period can be calculated as follows:

Risk of CHD death by time $t, p(t)=1-\exp (-\exp ((\log (t)-X \beta) / \sigma))$

where $\mathrm{X}$ is the vector of risk factors, $\beta$ is the vector of coefficients and $\sigma$ is a scale parameter which is also estimated. This model has previously been used in the Framingham study to describe risk profiles and the effects of risk factors on coronary outcomes through the Framingham risk score.(24)

For each man in the analysis, we used the above equation to calculate the risk of CHD based on his observed risk factors with age constrained to 55 years. These risks were summed up for all men and tabulated by employment grade to give the baseline expected number of CHD deaths prior to any intervention. To estimate the effect on CHD risk of each risk factor intervention, we applied the intervention to each man and re-computed the risk of CHD using the risk equation. To estimate the effect of a $50 \%$ reduction in nonIDDM prevalence we randomly assigned half of the men with non-IDDM to non- 
diabetics. We repeated this random allocation five times and averaged the expected CHD risk. Sensitivity analyses constraining the age to either 50 or 60 years changed the risk of CHD but had little effect on the percentage changes in excess risk or the risk ratio between low and high employment grade. Using separate equations to estimate the effects of best-practice interventions for each specific risk factor on CHD mortality yielded results very similar to those based on a model with all risk factors included simultaneously. Thus, only the latter analysis is reported here.

\section{Estimation for primordial prevention}

Primordial prevention aims to change the conditions that determine risk factor development, thus successful prevention will eliminate the risk factors themselves. We model the effect of such prevention by applying the best-practice intervention to all men irrespective of their risk levels and additionally setting an optimal risk profile (i.e., systolic blood pressure $\leq 120 \mathrm{~mm} \mathrm{Hg}$, total cholesterol $\leq 5.0 \mathrm{mmol} / \mathrm{L}$, postload blood glucose $\leq 4.6 \mathrm{mmol} / \mathrm{L}$, no non-IDDM and never smoking) for those who had residual nonoptimal risk levels or were ex-smokers after the best-practice interventions (IDDM remained unchanged). In all other respects, the modelling corresponds to that described for the best-practice interventions.

\section{Role of the funding source}

The study sponsors had no role in study design; in the collection, analysis, and interpretation of data; in the writing of the report; or in the decision to submit the paper for publication. The corresponding author had full access to all the data in the study and had final responsibility for the decision to submit for publication. 


\section{RESULTS}

Men from the low employment grades generally had a less favourable risk profile than men from the high grades (table 1). Systolic blood pressure, glucose and the proportions of current smokers and non-insulin dependent diabetics were higher in the low employment grade group. However, total cholesterol levels were slightly greater in the high grade group.

\section{Best practice and primordial interventions - Effect on CHD mortality}

During the 15-year follow-up, 1262 men died from CHD. As expected, low employment grade and all of the risk factors were associated with elevated mortality (Table 2). Including best practice interventions in the model resulted in an overall decrease of $57 \%$ in the risk of CHD mortality at age 55. Lowering cholesterol alone was associated with a $33 \%$ reduction in CHD death. Corresponding reductions for the other risk factors were $23 \%$ for smoking, $14 \%$ for high blood pressure, but only $2 \%$ for intervening in diabetes risk.

The primordial prevention model suggested that removing all risk factors from the study population reduces CHD mortality by $73 \%$. Risk reductions associated with the risk factors individually were $32 \%$ for high blood pressure, $33 \%$ for high cholesterol, $3 \%$ for diabetes and $37 \%$ for smoking.

\section{Best practice interventions}

Fifteen-year risk of CHD death at age 55 is 11.0 per 100 for men in the low employment grades and 7.5 for those in the high grades, a between-group risk difference of 3.5 (table 3). Including best practice interventions in the model reduced this risk difference by $43 \%$ 
for smoking, $31 \%$ for cholesterol, $13 \%$ for blood pressure, and $6 \%$ for diabetes risk. All these interventions together reduced the 15 -year CHD mortality to 4.4 per 100 for men in the low grades and 3.3 for men in the high grades. Thus, the estimated post-intervention risk difference between high and low employment grade groups is 1.1, a reduction in absolute risk disparity of $69 \%$.

In relative terms, the ratio of 15 -year CHD mortality risk between the high and low employment grade groups is 1.46 and the corresponding post-intervention risk ratio is 1.32. The overall $30 \%$ reduction in the risk ratio is almost entirely attributable to the effect of smoking cessation which accounted for $28 \%$. As employment grade differences in the prevalence of other coronary risk factors were small, best practice intervention reducing these risk factors has little effect on the relative risk associated with low socioeconomic position.

\section{Primordial prevention - effect on socioeconomic inequalities in CHD mortality}

Interventions that reduced all the outstanding non-optimal levels of risk to optimal levels and completely eliminated non-IDDM and smoking (i.e. all men considered to be never smokers) further reduced the population means: systolic blood pressure $115.0 \mathrm{~mm} \mathrm{Hg}$, cholesterol $3.1 \mathrm{mmol} / \mathrm{L}$, post-load glucose among non-diabetics $4.0 \mathrm{mmol} / \mathrm{L}$, and no exposure to smoking. The 15-year CHD mortality risk under these circumstances is 2.2 per 100 in the high grade men and 2.7 in the low grade men. This represents an overall reduction in absolute risk disparity of $86 \%$. For relative risk, the reduction in socioeconomic disparities is $53 \%$, with smoking and blood pressure the most important contributing factors. 


\section{DISCUSSION}

The aim of the present study was to examine the extent to which the successful implementation of best-practice interventions to modify CHD risk factors could reduce socioeconomic inequalities in CHD mortality at a population level. According to estimates from the Whitehall population, best practice interventions to reduce classic coronary risk factors, if successfully implemented in both high and low socioeconomic groups, could eliminate $69 \%$ of the difference in CHD risk between these groups.

Cholesterol lowering and smoking cessation account for the largest part of this beneficial change. Primordial prevention, a hypothetical intervention that successfully reduces all risk factors to optimal levels (including all men being lifelong non-smokers), would, we estimate, confer only modest further benefits. In relative terms, best practice interventions and primordial prevention were not as successful in reducing relative inequalities in CHD between socioeconomic groups.

\section{Effect of best pharmacological and lifestyle interventions}

Numerous population-based cohort studies have examined the contribution of the classic risk factors to relative socioeconomic inequalities ignoring the contribution to absolute differences in CHD between the socioeconomic groups. Our quantification suggests that using interventions shown to affect the greatest reduction in CHD in randomised controlled trials (best practice interventions) reduces the relative difference in CHD between high and low socioeconomic groups only by $30 \%$. Previous studies using adjustment-based approaches suggest a similar reduction of $15 \%$ to $40 \%$ in relative risk. $(5,7)$ The adjustment-based method differs from ours in that it approximates what would happen after standardization to the risk factor distribution in the total study population irrespective of whether this is possible. 
Smoking cessation for all smokers made the greatest contribution to both relative and absolute difference in CHD between high and low socioeconomic groups. Reductions in other risk factors had only a modest effect on relative inequalities in CHD. Although smoking cessation for all smokers is the ultimate aim of all health policy, this may seem a very optimistic goal at a population level. Re-calculating the overall best-practice intervention effect with smoking prevalence only halved suggests a 55\% (rather than $69 \%$ ) drop in mortality differences between high and low grades and a $12 \%$ (not $30 \%$ ) reduction in the relative risk. In this scenario, total cholesterol reduction becomes the factor that generates the greatest reduction in absolute socioeconomic disparities in CHD mortality.

The relative approach to socioeconomic inequalities is only sensitive to reductions in risk factors that are socially patterned. As cholesterol levels were not higher in low socioeconomic groups, reduction in cholesterol did not reduce relative socioeconomic inequalities in CHD mortality despite resulting in substantial reduction in the CHD mortality difference between the socioeconomic groups. This starkly illustrates that the determinants of relative socio-economic inequalities may be different to the determinants of absolute differences.(5)

\section{Total removal of the classic coronary risk factors}

The proportion of people who had optimal risk factor levels was very small; $<2 \%$ in our cohort. Other studies, with less stringent criteria, found $15 \%$ in a Finnish sample(5) and $5 \%$ in a multiracial study of men in the US Atherosclerosis Risk in Communities study.(9) Getz et al calculated that in Norway, one of the healthiest nations in the world, about $86 \%$ 
of men at age 40 would be classified as high risk and none at low risk using the 2003 European guidelines criteria.(25)

Although there are currently no evidence-based strategies or tools to completely eliminate the classic coronary risk factors from the total population, this may not necessarily be the case in the future. In addition to best-practice prevention, interventions that target upstream risk factors, such as the psychosocial and material circumstances in which people live and work, are suggested to be effective in reducing relative inequalities.(2628) Lifetime risk factor prevention starting early in life is often seen as the key to eliminating most CHD and reducing absolute differences between socioeconomic groups.(29) The two prevention strategies are not mutually exclusive. For example, attempts to reduce smoking levels in populations through fiscal policy will both prevent initiation of smoking (and ultimately may essentially eliminate smoking) and reduce absolute differences in smoking levels between social class groups (even if relative differences increase).

Our analysis suggests that any prevention programme that completely eliminates the four classic coronary risk factors from the population would reduce CHD deaths by $73 \%$ and absolute socioeconomic disparities by $86 \%$. True primordial prevention strategies may have even greater potential than suggested here, as for several factors we only categorise risk according to measures taken in middle-life. We do not have estimates of risk associated with lifetime low levels of circulating cholesterol, which will be lower than those associated with low levels at only one stage of the lifecourse. Recent studies that have examined genetic variants associated with different lifetime levels of cholesterol have shown that reductions in CHD risk obtained in randomised controlled trials of 
relatively short (less than 10 year) treatment duration, and observational studies initiated when the study members were middle aged, under-estimate the absolute differences in CHD rates associated with longer-term differences in cholesterol levels. $(30,31)$ The same logic applies to other classic risk factors. In isolated, non-westernised populations with a non-sedentary lifestyle and a low-fat diet free of added salt and refined carbohydrate, such as the Yanomamo Indians, average systolic blood pressure is about $100 \mathrm{~mm} \mathrm{Hg}$, total cholesterol $3.1 \mathrm{mmol} / \mathrm{L}$, and there is little evidence of cardiovascular deaths among these people. $(19,32)$ Thus we will be under-estimating the potential of true primordial prevention in our analyses. A caveat that would influence estimates in the opposite direction, but probably to a lesser extent, is that a small proportion of individuals with marked genetically-influenced elevations in cholesterol, glucose or blood pressure(33-36) would have levels above those used as our cut-offs.

\section{Strengths and limitations}

The validity of our estimates depends on the underlying assumptions and the data used. Instead of risk factor categories, we used continuous measures of blood pressure, cholesterol and blood glucose. This may have improved precision. Our analyses of possible risk factor reductions were based on the effects of best practice interventions derived from randomised controlled trials or, where possible, meta-analyses of such trials, that is, the strongest possible evidence.(11-13) This approach may provide a more realistic estimation for policy than those based on risk factor standardisation or comparisons of exposed and unexposed groups. Differential treatment between socioeconomic groups is an unlikely source of bias in this study as treatment for blood pressure was very limited ( $1.7 \%$ in both high and low grades) and effective cholesterol-lowering interventions had yet to become available.(21) Obtaining the prevalence of risk factors and associated 
excess risks of CHD from the same population (rather than from different populations) is also a strength of this study.

Our study of course is not without its limitations. First, the findings are based on data from a male occupational cohort and it could be argued may not translate to women or to non-working populations. However, differences between the participants and British men aged 45-64 in 2003 were small for total cholesterol (5.1 vs $5.5 \mathrm{mmol} / \mathrm{L})$ and systolic blood pressure (137 vs $135 \mathrm{~mm} \mathrm{Hg})(15)$ and there is little evidence of differences in the effects on cardiovascular disease of the studied risk factors between men and women, except for greater diabetes-related risk of fatal CHD in women. $(37,38)$ Prevalence of smoking was high in this study population compared to more contemporary populations and is likely to overemphasise the role of this behaviour in generating absolute socioeconomic inequalities.

Second, we estimated the benefits from interventions for each risk factor separately while controlling for others. However, we did not take into account the potential interaction effects between different risk reductions because comparable clinical evidence relates to single- rather than multiple-factor interventions. Our predictive models were also unable to capture lag effects or time trends in risk factors and CHD mortality.(39) Further, we estimated the benefits of best practice risk factor reductions in terms of reduced CHD mortality from observational data which are open to confounding. Despite these potential limitations, our estimates of intervention effects did not substantially deviate from those reported for CHD morbidity and mortality in clinical trials: an estimated $33 \%$ reduction in CHD from cholesterol lowering in this study versus $20 \%-36 \%$ reductions observed in lipid lowering trials;(40) a 15\% reduction for systolic blood pressure lowering in our 
analysis versus 10\%-20\% reductions in relative risk of cardiovascular events in blood pressure lowering trials.(41) Although observational data suggest these reductions may be dependent on age, trials provide little evidence of any age-specific effects, supporting our analysis combining all age groups. $(40,41)$ As we discuss above, with lifetime reductions in these risk factors, greater effects than those predicted in our observational data or seen in short-term randomized controlled trials would be expected.

Finally, we assumed that best practice interventions are implemented equitably and have similar effectiveness in both high and low socioeconomic groups. Obviously, this is a major challenge for policy as there are many barriers to realizing the full potential of interventions in all groups. These include unhealthy environments not conductive to salubrious modes of life, together with limited financial and health care resources. These constraints disproportionately affect low socioeconomic groups.(3)

\section{Conclusion}

This study provides an example of a novel way of quantifying socioeconomic inequalities in health. Although the aim of health practitioners and governments is to reduce the classic coronary risk factors to optimal levels and eliminate smoking, population-wide comprehensive screening and best practice interventions remain to be implemented. Our estimations from a working population suggest that such interventions, if implemented equally successfully in high and low socioeconomic groups, would eliminate most of the socioeconomic inequalities in CHD. 


\section{Contributors}

MK, GDS, ASM and MJS designed the original hypothesis which other authors further elaborated. MJS in collaboration with MK and GDS ran all the analyses. MK wrote the first draft of the report except the statistical section which was written by MJS. All authors interpreted the results, revised the report, and approved the final version of the report.

\section{Conflict of interest statement}

We declare that we have no conflict of interest.

\section{Acknowledgements}

The original screening of the Whitehall study was funded by the Department of Health and Social Security and the Tobacco Research Council. MK, also at the Finnish Institute of Occupational Health, is supported by the Academy of Finland. MJS is supported by the British Heart Foundation, JEF by the Medical Research Council, and ASM by the European Research Council. GDB is a Wellcome Trust fellow. MGM is a Medical Research Council Research Professor and at the time of this work was supported by WHO Commission on Determinants of Socioeconomic Inequalities in Health, which he chaired. 


\section{REFERENCES}

1. Acheson D. Independent inquiry into inequalities in health. Report. London; 1998.

2. Black D. Inequalities in health: Report of a working group chaired by Sir Douglas Black. London: Department of Health and Social Security; 1980.

3. CSDH. Closing the gap in a generation: health equity through action on the social determinants of health. Final Report of the Commission on Social Determinants of Health. Geneva: World Health Organization; 2008.

4. Marmot MG, Shipley MJ, Rose G. Inequalities in death--specific explanations of a general pattern? Lancet 1984; 8384: 1003-6.

5. Lynch J, Davey Smith G, Harper S, Bainbridge K. Explaining the social gradient in coronary heart disease: comparing relative and absolute risk approaches. $J$ Epidemiol Community Health 2006; 60: 436-41.

6. Singh-Manoux A, Nabi H, Shipley M, Guéguen A, Sabia S, Dugravot A, et al. The role of conventional risk factors in explaining social inequalities in coronary heart disease: the relative and absolute approaches to risk. Epidemiol 2008; 19: 599-605.

7. Khang YH, Lynch JW, Jung-Choi K, Cho HJ. Explaining age-specific inequalities in mortality from all causes, cardiovascular disease and ischaemic heart disease among South Korean male public servants: relative and absolute perspectives. Heart 2008; 94: 75-82.

8. Greenland P, Knoll MD, Stamler J, Neaton JD, Dyer AR, Garside DB, et al. Major risk factors as antecedents of fatal and nonfatal coronary heart disease events. JAMA 2003; 290: 891-7.

9. Hozawa A, Folsom AR, Sharrett AR, Chambless LE. Absolute and attributable risks of cardiovascular disease incidence in relation to optimal and borderline risk factors: comparison of African American with white subjects--Atherosclerosis Risk in Communities Study. Arch Intern Med 2007; 167: 573-9.

10. Yusuf S, Reddy S, Ounpuu S, Anand S. Global burden of cardiovascular diseases: part I: general considerations, the epidemiologic transition, risk factors, and impact of urbanization. Circulation 2001; 104: 2746-53.

11. Fahey T, Schroeder K, Ebrahim S. Interventions used to improve control of blood pressure in patients with hypertension. Cochrane database of systematic reviews (Online). 2006(4):CD005182. 
12. Edwards JE, Moore RA. Statins in hypercholesterolaemia: a dose-specific metaanalysis of lipid changes in randomised, double blind trials. BMC Fam Pract $2003 ; 4: 18-25$.

13. Yamaoka K, Tango T. Efficacy of lifestyle education to prevent type 2 diabetes: a meta-analysis of randomized controlled trials. Diabetes Care 2005; 28: 2780-6.

14. Jha P, Peto R, Zatonski W, Boreham J, Jarvis MJ, Lopez AD. Social inequalities in male mortality, and in male mortality from smoking: indirect estimation from national death rates in England and Wales, Poland, and North America. Lancet 2006; 368: 367-70.

15. National-Statistics. Risk Factors for Cardiovascular Disease. London: Department of Health; 2003.

16. Eyer J. Hypertension as a disease of modern society. Int J Health Serv 1975; 5: $539-58$.

17. Zimmet $\mathbf{P}$, Arblaster $\mathrm{M}$, Thoma $\mathrm{K}$. The effect of westernization on native populations. Studies on a Micronesian community with a high diabetes prevalence. Aust New Zeal JMed 1978; 8: 141-6.

18. O'Dea K. Diabetes in Australian aborigines: impact of the western diet and life style. J Intern Med 1992; 232: 103-17.

19. Mancilha-Carvalho JJ, Crews DE. Lipid profiles of Yanomamo Indians of Brazil. Prev Med 1990; 19: 66-75.

20. Brunner EJ, Shipley MJ, Witte DR, Fuller JH, Marmot MG. Relation between blood glucose and coronary mortality over 33 years in the Whitehall Study. Diabetes Care 2006; 29: 26-31.

21. Reid DD, Brett GZ, Hamilton PJ, Jarrett RJ, Keen H, Rose G. Cardiorespiratory disease and diabetes among middle-aged male Civil Servants. A study of screening and intervention. Lancet 1974; 1: 469-73.

22. Rose GA, Holland WW, Crowley EA. A Sphygmomanometer for Epidemiologists. Lancet 1964; 1: 296-300.

23. Rose G, Shipley M. Effects of coronary risk reduction on the pattern of mortality. Lancet 1990; 335: 275-7.

24. Anderson KM, Wilson PWF, Odell PM, Kannel WB. An updated coronary risk profile. Circulation 1991; 83: 356-62.

25. Getz L, Sigurdsson JA, Hetlevik I, Kirkengen AL, Romundstad S, Holmen J. Estimating the high risk group for cardiovascular disease in the Norwegian HUNT 
2 population according to the 2003 European guidelines: modelling study. $B M J$ 2005; 331: 551-5.

26. Marmot MG, Davey Smith G, Stansfeld S, Patel C, North F, Head J, et al. Health inequalities among British civil servants: the Whitehall II study. Lancet 1991; 337: 1387-93.

27. Marmot M. Achieving health equity: from root causes to fair outcomes. Lancet 2007; 370: 1153-63.

28. Lynch JW, Davey Smith G, Kaplan GA, House JS. Income inequality and mortality: importance to health of individual income, psychosocial environment, or material conditions. BMJ 2000; 320: 1200-4.

29. Stamler J, Stamler R, Neaton JD, Wentworth D, Daviglus ML, Garside D, et al. Low risk-factor profile and long-term cardiovascular and noncardiovascular mortality and life expectancy: findings for 5 large cohorts of young adult and middle-aged men and women. JAMA 1999; 282: 2012-8.

30. Cohen JC, Boerwinkle E, Mosley TH, Jr., Hobbs HH. Sequence variations in PCSK9, low LDL, and protection against coronary heart disease. $N$ Engl J Med 2006; 354: 1264-72.

31. Davey Smith G, Ebrahim S. Mendelian randomization: prospects, potentials, and limitations. Int J Epidemiol 2004; 33: 30-42.

32. Mancilha-Carvalho JJ, de Oliveira R, Esposito RJ. Blood pressure and electrolyte excretion in the Yanomamo Indians, an isolated population. J Hum Hypertens 1989; 3: 309-14.

33. Durrington P. Dyslipidaemia. Lancet 2003; 362: 717-31.

34. Rother KI. Diabetes treatment--bridging the divide. NEngl J Med 2007; 356: 1499-501.

35. Lifton RP, Dluhy RG, Powers M, Rich GM, Gutkin M, Fallo F, et al. Hereditary hypertension caused by chimaeric gene duplications and ectopic expression of aldosterone synthase. Nat Genet 1992; 2: 66-74.

36. Simon DB, Bindra RS, Mansfield TA, Nelson-Williams C, Mendonca E, Stone R, et al. Mutations in the chloride channel gene, CLCNKB, cause Bartter's syndrome type III. Nat Genet 1997; 17: 171-8.

37. Yusuf S, Hawken S, Ounpuu S, Dans T, Avezum A, Lanas F, et al. Effect of potentially modifiable risk factors associated with myocardial infarction in 52 
countries (the INTERHEART study): case-control study. Lancet 2004; 364: 93752.

38. Huxley R, Barzi F, Woodward M. Excess risk of fatal coronary heart disease associated with diabetes in men and women: meta-analysis of 37 prospective cohort studies. $B M J 2006 ; 332: 73-8$.

39. Mathers CD, Loncar D. Projections of global mortality and burden of disease from 2002 to 2030. PLoS Med 2006; 3: e442.

40. Baigent C, Keech A, Kearney PM, Blackwell L, Buck G, Pollicino C, et al. Efficacy and safety of cholesterol-lowering treatment: prospective meta-analysis of data from 90,056 participants in 14 randomised trials of statins. Lancet 2005; 366: $1267-78$.

41. Fuchs FD. Effects of different blood-pressure-lowering regimens on major cardiac events. Lancet 2004; 363: 332. 
Table 1. Age-adjusted means/prevalence of risk factors and CHD mortality by employment grade.

\begin{tabular}{|c|c|c|c|c|}
\hline & \begin{tabular}{l}
\multicolumn{1}{c}{ High } \\
employment \\
grade
\end{tabular} & $\begin{array}{l}\text { Low } \\
\text { employment } \\
\text { grade }\end{array}$ & $\begin{array}{l}\text { Difference } \\
\text { (low grade - } \\
\text { high grade) }\end{array}$ & p-Value \\
\hline No. of participants & 12644 & 4542 & & \\
\hline Age, years & $50.9(0.1)$ & $55.5(0.1)$ & 4.7 & $<0.001$ \\
\hline Systolic blood pressure, $\mathrm{mm} \mathrm{Hg}$ & $136.3(0.2)$ & $137.3(0.3)$ & 1.0 & 0.01 \\
\hline Total cholesterol, $\mathrm{mmol} / \mathrm{L}$ & $5.12(0.01)$ & $5.02(0.02)$ & -0.10 & $<0.001$ \\
\hline IDDM, \% (n) & $0.3(32)$ & $0.2(9)$ & -0.1 & 0.55 \\
\hline Non IDDM, \% (n) & $0.7(82)$ & $1.6(91)$ & 0.9 & $<0.001$ \\
\hline $\begin{array}{l}\text { Postload blood glucose for non- } \\
\text { diabetics, } \mathrm{mmol} / \mathrm{L}\end{array}$ & $4.15(0.01)$ & $4.20(0.01)$ & 0.05 & $<0.001$ \\
\hline Current smoking, \% (n) & $36.7(4625)$ & $56.0(2550)$ & 19.3 & $<0.001$ \\
\hline Optimal risk factor profile*, \% (n) & $1.8(244)$ & $1.1(34)$ & -0.7 & 0.003 \\
\hline $\begin{array}{l}\text { 15-year CHD mortality, rate† (no. } \\
\text { of deaths) }\end{array}$ & $4.91(748)$ & $7.06(514)$ & 2.15 & $<0.001$ \\
\hline
\end{tabular}

IDDM, insulin dependent diabetes mellitus; Non IDDM, non-insulin dependent diabetes mellitus.

*Blood pressure $\leq 120 \mathrm{mmHg}$; cholesterol concentration $\leq 5.0 \mathrm{mmol} / \mathrm{L}$; postload blood glucose $\leq 4.6 \mathrm{mmol} / \mathrm{L}$; never smoker.

$\uparrow$ Age standardised CHD mortality rate per 1000 person years. 
Table 2. Best practice interventions and primordial prevention - Effects on coronary heart disease mortality

\begin{tabular}{|c|c|c|c|c|c|}
\hline & \multirow{2}{*}{$\begin{array}{c}\text { Hazard ratio* } \\
\text { (95\% CI) for } \\
15-y \text { CHD } \\
\text { mortality }\end{array}$} & \multicolumn{2}{|c|}{ Best-practice intervention } & \multicolumn{2}{|c|}{ Primordial prevention } \\
\hline & & Effect & $\begin{array}{l}\text { Change in risk of } \\
\text { CHD mortality }\end{array}$ & Post-prevention level & $\begin{array}{l}\text { Change in risk of CHD } \\
\text { mortality }\end{array}$ \\
\hline Systolic blood pressure, per $10 \mathrm{~mm} \mathrm{Hg}$ & $1.18(1.15,1.20)$ & $\downarrow 10 \mathrm{~mm} \mathrm{Hg}$ & $-14 \%$ & $\leq 120 \mathrm{~mm} \mathrm{Hg}$ & $-32 \%$ \\
\hline Total cholesterol, per $2 \mathrm{mmol} / \mathrm{L}$ & $1.51(1.39,1.65)$ & $\downarrow 2 \mathrm{mmol} / \mathrm{L}$ & $-33 \%$ & $\leq 5 \mathrm{mmol} / \mathrm{L}$ & $-33 \%$ \\
\hline IDDM, yes vs glucose referencet & $1.79(0.74,4.32)$ & No change in IDDM & $0 \%$ & No change in IDDM & $0 \%$ \\
\hline Non-IDDM, yes vs glucose reference $\dagger$ & $2.55(1.84,3.54)$ & $\downarrow 50 \%$ prevalence & & No non-IDDM & \\
\hline $\begin{array}{l}\text { Postload blood glucose, per unit } \\
\text { increase after } 4.6 \mathrm{mmol} / \mathrm{L}\end{array}$ & $1.14(1.03,1.25)$ & $\begin{array}{l}\downarrow 1 \mathrm{mmol} / \mathrm{L} \text { postload } \\
\text { glucose for non- } \\
\text { diabetics }\end{array}$ & $-2 \% \%$ & $\leq 4.6 \mathrm{mmol} / \mathrm{L}$ & $-3 \% *$ \\
\hline Current smoking, yes vs no & $1.78(1.59,2.00)$ & Smoker $\rightarrow$ non-smoker & $-23 \%$ & Never smoking & $-37 \%$ \\
\hline All risk factors & N/A & All above & $-57 \%$ & All above & $-73 \%$ \\
\hline
\end{tabular}

* Hazard ratios are mutually adjusted and also adjusted for age and employment grade.

$\dagger$ Reference group is those with blood glucose $\leq 4.6 \mathrm{mmol} / \mathrm{L}$.

$\$$ Combined effect of interventions targeting non-IDDM and high post-load blood glucose. 
Table 3. Best practice interventions and primordial prevention - Effect on excess risk and relative risk of CHD mortality for low versus high employment grades.

\begin{tabular}{|c|c|c|c|c|c|c|}
\hline \multirow[t]{2}{*}{ Intervention/prevention } & \multicolumn{2}{|c|}{ 15-y risk* of CHD death } & \multirow{2}{*}{$\begin{array}{l}\text { Excess } \\
\text { risk }\end{array}$} & \multirow{2}{*}{$\begin{array}{c}\text { Change } \\
\text { in excess } \\
\text { risk }\end{array}$} & \multirow{2}{*}{$\begin{array}{c}\text { Relative } \\
\text { risk } \\
\text { ratio }\end{array}$} & \multirow{2}{*}{$\begin{array}{c}\text { Change in } \\
\text { relative risk } \\
\text { ratio }\end{array}$} \\
\hline & $\begin{array}{l}\text { High } \\
\text { employment } \\
\text { grade }\end{array}$ & $\begin{array}{l}\text { Low } \\
\text { employment } \\
\text { grade }\end{array}$ & & & & \\
\hline \multicolumn{7}{|l|}{ Best practice intervention } \\
\hline None & 7.5 & 11.0 & 3.5 & Reference & 1.458 & Reference \\
\hline Systolic BP: $\downarrow 10 \mathrm{~mm} \mathrm{Hg}$ & 6.4 & 9.4 & 3.0 & $-13 \%$ & 1.465 & $+2 \%$ \\
\hline Total cholesterol: $\downarrow 2 \mathrm{mmol} / \mathrm{L}$ & 5.1 & 7.5 & 2.4 & $-31 \%$ & 1.473 & $+3 \%$ \\
\hline IDDM prevalence: no change & 7.5 & 11.0 & 3.5 & $0 \%$ & 1.458 & $0 \%$ \\
\hline $\begin{array}{l}\text { Non IDDM prevalence: } \downarrow 50 \% \\
\text { Non-diabetics: } \downarrow 1 \mathrm{mmol} / \mathrm{L} \text { glucose } \uparrow\end{array}$ & 7.4 & 10.7 & 3.3 & $-6 \%$ & 1.441 & $-4 \%$ \\
\hline Smoker $\rightarrow$ non-smoker & 6.0 & 7.9 & 2.0 & $-43 \%$ & 1.331 & $-28 \%$ \\
\hline All above & 3.3 & 4.4 & 1.1 & $-69 \%$ & 1.323 & $-30 \%$ \\
\hline \multicolumn{7}{|l|}{ Primordial prevention } \\
\hline None & 7.8 & 11.5 & 3.8 & Reference & 1.486 & Reference \\
\hline Systolic BP to $\leq 120 \mathrm{~mm} \mathrm{Hg}$ & 5.4 & 7.5 & 2.2 & $-43 \%$ & 1.402 & $-17 \%$ \\
\hline Total cholesterol to $\leq 5.0 \mathrm{mmol} / \mathrm{L}$ & 5.2 & 7.8 & 2.6 & $-31 \%$ & 1.504 & $+4 \%$ \\
\hline Non IDDM: no change & 7.8 & 11.5 & 3.8 & $0 \%$ & 1.486 & $0 \%$ \\
\hline $\begin{array}{l}\text { No non-IDDM and postload } \\
\text { glucose to } \leq 4.6 \mathrm{mmol} / \mathrm{L} \text { glucose } \uparrow\end{array}$ & 7.6 & 11.0 & 3.4 & $-9 \%$ & 1.453 & $-7 \%$ \\
\hline Ever smoking to never smoking & 5.1 & 6.9 & 1.8 & $-52 \%$ & 1.356 & $-27 \%$ \\
\hline All above & 2.2 & 2.7 & 0.5 & $-86 \%$ & 1.231 & $-53 \%$ \\
\hline
\end{tabular}

* 15 -year risk of $\mathrm{CHD}$ death per 100 men, adjusted to age 55.

$\uparrow$ Combined effect of interventions targeting non-IDDM and high post-load blood glucose. 